\title{
Anti-Proliferative and Antimicrobial Activity of Methanolic Extract and SPE Fractions of Artemisia spicigera
}

\author{
Fariba Heshmati Afshar, ${ }^{1,2}$ Parina Asgharian,, Laleh Khodaie, ${ }^{1,3,}$ Abbas Delazar,, ${ }^{1,2}$ Farzaneh Lotfipour, ${ }^{4}$ \\ and Behzad Baradaran ${ }^{1}$ \\ ${ }^{1}$ Drug Applied Research Center, Tabriz University of Medical Sciences, Tabriz, Iran \\ ${ }^{2}$ Department of Pharmacognosy, Faculty of Pharmacy, Tabriz University of Medical Sciences, Tabriz, Iran \\ ${ }^{3}$ Department of Phytopharmacy, Faculty of Traditional Medicine, Tabriz University of Medical Sciences, Tabriz, Iran \\ ${ }^{4}$ Department of Pharmaceutical and Food Control, Faculty of pharmacy, Tabriz University of Medical Sciences, Tabriz, Iran \\ "Corresponding author: Laleh Khodaie, Department of Traditional Pharmacy, Faculty of Traditional Medicine, Tabriz University of Medical Sciences, Tabriz, Iran. Tel: \\ +98413-3379527-29, +98-9144136408, Fax: +98-413-3339527-29, E-mail: khodaiel@gmail.com
}

Received 2016 February 13; Revised 2016 October 02; Accepted 2016 October 10.

\begin{abstract}
Objectives and Methods: This study was conducted to investigate in vitro, methanolic extract and methanol/water fractions obtained from the arial parts of Artemisia spicigera C. Koch (Asteraceae family) and for evaluation of their antiproliferative effects against HT-29, L-929 and A 549 cell lines by MTT assay at different concentrations $(1,10,100,1000 \mu \mathrm{g} / \mathrm{mL})$. Furthermore, this study aimed to detect antimicrobial activities of the mentioned samples: two Gram-positive (Staphylococcus epidermidis and Staphylococcus aureus), two Gram-negative bacteria (Pseudomonas aeruginosa and Escherichia coli) and a fungi (Candida albicanse), using agar well diffusion method.

Results: The IC50 values for antiproliferative activity of the methanolic extract, $20 \%, 40 \%$ and $60 \%$ SPE (solid phase extraction) fractions, found to be $345.91 \pm 28.77,442.44 \pm 83.22,220.19 \pm 43.13$ and $579.90 \pm 153.19 \mu \mathrm{g} / \mathrm{mL}$, respectively; in this case, the maximum inhibition percentage belonged to $40 \%$ SPE fraction $(220.19 \pm 43.13 \mu \mathrm{g} / \mathrm{mL})$. The total methanolic extract of A. spicigera indicated inhibitory activity against Gram- positive strains, S. epidermidis and S. aureus, with MIC values of $150 \mathrm{mg} / \mathrm{mL}$ for both bacteria. Among SPE fractions, $20 \%$ was the only active one against Gram possitive species with MIC values of $35 \mathrm{mg} / \mathrm{mL}$ for both strains.

Conclusions: This study revealed that methanolic extract of A. spicigera and its SPE fractions might be regarded as bioactive natural products, which deserves to be further identification and isolation of cytotoxic and antibacterial phytochemicals from them.
\end{abstract}

Keywords: Artemisia, Antiproliferative, Antimicrobial, Asteraceae, Flavonoid, MTT

\section{Background and Objectives}

Recently, researchers have shown an increasing interest in the biological activities of medicinal plants. Over $60 \%$ of the antibacterial and cytotoxic agents are either natural substances, or derivatives of them (1). Genus Artemisia with the common Persian name of "Dermane" belonging to Asteraceae (Compositeae) family contains 34 species wildly growing in Iran $(2,3)$. Isolated biologically active secondary metabolites from plants of this genus showed a variety of pharmacological activities, including anti-microbial, anti-viral, anti-tumoral, antipyretic, anti-malarial, anti-haemorrhagic, anti-coagulant, and anti-inflammatory, anti-oxidant, anti-hepatitis, antiulcerogenic and anti-spasmodic effects (4-10). Artemisia spicigera known as "Dermane ye sonbolei" in Persian language, is an aromatic herb growing in the North and Northwestern parts of Iran (5). According to the previous studies, many biological activities assayed on different extracts of this plant showed the antioxidant (11), antimalar- ial and insecticidal activities of the tested samples (12). Although several studies have been conducted to assess the antimicrobial and antiproliferative activities of the extracts from different species of Artemisia, to our knowledge, no data were available on the antibacterial and antiproliferative effects of methanolic extract and SPE fractions of A. spicigera. Hence, the aim of this study was to determine the mentioned biological activities of the tested samples.

\section{Methods}

\subsection{Plant Material and Preparing the Extracts}

Aerial parts of Artemisia spicigera C. Koch were collected from Julfa, border of Aras river in East Azarbaijan province, Iran in 2009. A Voucher specimen of this collection (TbzFPH 716) has been deposited at the herbarium of the pharmacy faculty, Tabriz University of Medical Sciences, Tabriz, Iran. 
Air-dried and ground aerial parts of A. spicigera (100 g) were successively Soxhlet-extracted, using n-hexane, dichloromethane (DCM) and methanol (MeOH) (1.1 L each). All the extracts were separately concentrated under vacuum by rotary evaporator, not exceeding the temperature of $50^{\circ} \mathrm{C}$, yielding $6.41 \mathrm{~g}, 1.45 \mathrm{~g}$ and $8.63 \mathrm{~g}$ of the extracts, respectively; $8 \mathrm{~g}$ of the dried $\mathrm{MeOH}$ extract was fractionated by solid-phase-extraction (SPE) on Sep-Pak (C18, $10 \mathrm{~g}$ cartridge), using a step gradient of $\mathrm{MeOH}$-water mixture (10:90, 20:80, 40:60, 60:40, 80:20 and 100:0), $200 \mathrm{~mL}$ each. Then all SPE fractions were dried, using a rotary evaporator at a temperature not exceeding $50^{\circ} \mathrm{C}$ yielding 1570,444 , $794,422,65$ and $670 \mathrm{mg}$ of $10 \%, 20 \%, 40 \%, 60 \%, 80 \%$ and $100 \%$ SPE fractions, respectively.

\subsection{Antiproliferative Activity}

\subsubsection{Cell Culture}

HT-29 (colon carcinoma cell line), L-929 (normal cell line) and A549 (adenocarcinoma human alveolar basal epithelial cells) cell lines were obtained from Pasture Institute, Tehran, Iran. All cell lines were grown in RPMI 1640 as a cell culture medium supplemented, with $10 \%$ fetal bovine serum (FBS), $100 \mathrm{mg} / \mathrm{mL}$ streptomycin and 100 units/mL penicillin G. They were incubated in a humidified air/carbon dioxide (95:5) atmosphere at $37^{\circ} \mathrm{C}$. At $75 \%$ confluence, phosphate buffered saline (PBS)/0.5\% ethylenediamine tetraacetate (EDTA) and $0.25 \%$ trypsin/ EDTA solution were used to rinse and harvest the cells from the flasks. Finally, cells were seeded in 96-well plate (Nunc, Denmark).

\subsubsection{MTT Assay}

MTT, a colorimetric, in vitro cell growth inhibition assay was used to evaluate the antiproliferative activity of A. spicigera $\mathrm{MeOH}$ extract and its fractions (13). For this purpose, $1 \times 10^{4}$ cells/well were seeded in to 96-well plate and incubated for 24 hours. Afterwards, different dilutions of $\mathrm{MeOH}$ extract and its fractions (1, 10, 100, $1000 \mu \mathrm{g} / \mathrm{mL}$ ) were prepared in dimethylsulfoxide (DMSO) and were diluted with cell culture medium. They were added to wells and then transferred into the incubator. After 48 hours of incubation, the medium was replaced with a fresh one, containing 3-(4,5-dimethylthiazol-2-yl)2,5-diphenyltetrazolium bromide reagent (MTT), which was dissolved in PBS to obtain $5 \mathrm{mg} / \mathrm{mL}$ solution. The medium was removed after four hours of incubation in the air /carbon dioxide (95:5) atmosphere at $37^{\circ} \mathrm{C}$, and 100 $\mu \mathrm{L}$ of DMSO was added to dissolve formazan crystals completely. Microplate reader (ELISA plate reader, Bio Teck, Bad Friedrichshall, Germany) was used at $570 \mathrm{~nm}$ wavelength to measure the optical density of the wells. Each assay was performed in triplicate. To compare the antiproliferative activity of the extract and its fractions, DMSO was considered as a negative control. Moreover, inhibitory rate was calculated by the following equation:

Relative viability $(\%)=$ (optical density of sample/optical density of control $) \times 100 . \quad \mathrm{IC}_{50}$ value was defined as the concentration of the $\mathrm{MeOH}$ extract to produce a 50\% reduction in the viability of the cells relative to the negative control, calculated from the dose-response curve plotted in the Sigma Plot 10 software.

\subsubsection{Antimicrobial Activity}

Bacterial cultures included Gram- negative species, including Pseudomonas aeruginosa (ATCC 9027) and Escherichia coli (ATCC 8739), as well as Gram- positive species Staphylococcus epidermidis (ATCC 12228), Staphylococcus aureus (ATCC 6538), and a fungi (Candida albicans) (ATCC) were used to evaluate antimicrobial properties of the $\mathrm{MeOH}$ extract of $A$. spicigera and its SPE fractions. Lyophilized form of the microbial strains was purchased from Pasture institute, Tehran, Iran. Centrifuged pellets of bacteria from a 24- hour culture were mixed with saline solution. Turbidity was corrected as per the standard of 0.5 McFarland [108 colony forming units (CFUs) per $\mathrm{mL}$ ] by adding sterile distilled water. Then the mentioned inoculums were used for seeding the Muller Hinton agar medium (MERCK). About $10 \mathrm{~mL}$ of the prepared inoculums $\left(10^{6}\right.$ CFUs per $\left.\mathrm{mL}\right)$ was seeded. The antimicrobial activity of the samples was monitored, using agar diffusion method, a highly recommended test for a routine assessment of preliminary antimicrobial screening. Each Muller Hinton petri plate was inoculated with a 0.5 McFarland's standard of selected bacteria, including five wells for test samples, two for solutions of the samples, and one for vehicle control (DMSO). Finally, $100 \mu \mathrm{L}$ of test solutions were poured in respective wells, and subsequently petri plates were incubated at $37^{\circ} \mathrm{C}$. After 24 hours of incubation, the diameter of the clear zones, indicating no bacterial growth, around each well (excluding well diameter) was measured, using the vernier caliper. Triplet plates were prepared for each sample. Samples showing significant antimicrobial activity were further assayed for their minimum inhibitory concentration (MIC), which is the lowest concentration of a fraction and has the ability to completely inhibit the growth of each bacterial strain. At First, serial two-fold dilutions of $\mathrm{MeOH}$ extract and its fractions were prepared in a nutrient broth. Second, control cultures, which did not influence bacterial growth were also prepared, containing sterile nutrient broth. Third, an equal volume of the adjusted inoculums were added to each test tube. Finally, MIC was read after 24 hours of incubation at $37^{\circ} \mathrm{C}$ (14). 


\section{Results}

Table 1 demonstrated the antiproliferative activity of the $\mathrm{MeOH}$ extract and SPE fractions of $A$. spicigera tested on HT29, A549 and L929 cell lines, which was evaluated using MTT assay. The IC 50 values extracted from the plots of cytotoxicity percentages, versus sample concentrations, presented the rate of antiproliferative activity of different samples. As displayed in Table $1, \mathrm{MeOH}$ extract and SPE fractions were not active against L929 and HT29, whereas $\mathrm{MeOH}$ extract indicated inhibitory activity against A549 cell line (345.91 $\pm 28.77 \mu \mathrm{g} / \mathrm{mL}$ ). Furthermore, the antiproliferative activity of $\mathrm{MeOH}$ extract, 20\%, 40\% and 60\% SPE fractions, were found to be $345.91 \pm 28.7,442.44 \pm 83.22$, $220.19 \pm 43.13$ and $579.9 \pm 153.19 \mu \mathrm{g} / \mathrm{mL}$, respectively. In this case, the maximum inhibition percentage belonged to $40 \%$ SPE fraction $(220.19 \pm 43.13)$. The results of the antimicrobial activity of the MeOH extract and SPE fractions of $A$. spicigera are presented in Table 2. The mean inhibition zone diameters (MIZD) as well as MIC values demonstrated the rate of activity against the susceptible strains. As demonstrated in Table 2, $\mathrm{MeOH}$ extract of A. spicigera indicated inhibitory activity against Gram-positive strains, $S$. epidermidis and S. aureus, with MIC value of $150 \mathrm{mg} / \mathrm{mL}$ for both susceptable species. Furthermore, among SPE fractions, $20 \%$ one was the only active sample against susceptible strains, with MIC values of $35 \mathrm{mg} / \mathrm{mL}$ for both species. Neither $\mathrm{MeOH}$ extract, nor SPE fractions showed activity against Gram- negative strains as well as Candida albicans.

Table 1. The Antiproliferative Activity of the MeOH Extract and SPE Fractions of $A$. Spicigera Tested by MTT Assay ${ }^{\mathrm{a}}$

\begin{tabular}{cccc}
\hline \multicolumn{3}{c}{ Cell Lines } \\
\hline Samples & HT 29 & A 549 & L 929 \\
\hline MeOH & $>1000$ & $345.91 \pm 28.77$ & $>1000$ \\
$\mathbf{1 0} \%$ & $>1000$ & $>1000$ & $>1000$ \\
$\mathbf{2 0} \%$ & $>1000$ & $579.9 \pm 153.19$ & $>1000$ \\
$\mathbf{4 0} \%$ & $>1000$ & $220.19 \pm 43.13$ & $>1000$ \\
$\mathbf{6 0} \%$ & $>1000$ & $442.44 \pm 83.22$ & $>1000$ \\
$\mathbf{8 0} \%$ & $>1000$ & $>1000$ & $>1000$ \\
$\mathbf{1 0 0} \%$ & $>1000$ & $>1000$ & $>1000$ \\
\hline
\end{tabular}

Abbreviations: $\mathrm{MeOH}$, Methanolic extract; 10\%, SPE fraction 10\% MeOH-water; $20 \%$, SPE faction $20 \% \mathrm{MeOH}$-water; $40 \%$, SPE fraction $40 \% \mathrm{MeOH}$-water; $60 \%$, SPE fraction $60 \% \mathrm{MeOH}$-water; $80 \%$, SPE fraction $80 \% \mathrm{MeOH}$-water; $100 \%$, SPE fraction $100 \% \mathrm{MeOH}$.

${ }^{a}$ Values are expressed as $\mathrm{IC}_{50}(\mu \mathrm{g} / \mathrm{mL}) \pm \mathrm{SD}(\mathrm{n}=3)$

\section{Discussion and Conclusion}

Plants are the valuable source for searching potential anticancer and antimicrobial agents (15). Moreover, the side effects of the current chemotherapeutical and antimicrobial drugs cause a severe reduction in the quality of life, leading to the development of novel agents (16). Prior studies have noted the importance of plants belonging to Artemisia genus to contain phyto constituents indicating anti proliferative activities which have potential of being used as therapeutic agents. For instance, DCM and $\mathrm{MeOH}$ extracts of $A$. ciniformis with $\mathrm{IC}_{50}$ values of 35 and $60 \mu \mathrm{g} / \mathrm{mL}$ showed antiproliferative activity against AGS cells. Moreover, HeLa cells were sensitive to both DCM extract of A. diffusa and ethyl acetate extract of $A$. ciniformis, with $\mathrm{IC}_{50}$ values of 71 and $73 \mu \mathrm{g} / \mathrm{mL}$, respectively. In addition, DCM extracts of A. diffusa, A. santolina Schrenk and A. ciniformis indicated inhibitory activity against HT-29 cells, with IC50 values of 42, 91 and $94 \mu \mathrm{g} / \mathrm{mL}$, respectively. Furthermore, the growth of MCF-7 cells were best inhibited by A. ciniformis DCM (IC I0 $_{50}$ value: $29 \mu \mathrm{g} / \mathrm{mL}$ ) and A. vulgaris L. ethyl acetate (IC Io $_{50}$ value: $57 \mu \mathrm{g} / \mathrm{mL}$ ) extracts (17). Moreover, the flower $\mathrm{MeOH}$ extract of A. absinthium and A. vulgaris were found to have cytotoxic effect on MCF-7 cell line, with an IC I0 $_{50}$ values of 221.5 and $>500 \mu \mathrm{g} / \mathrm{mL}$, respectively (18). According to $\mathrm{IC}_{50}$ values, displayed in Table 1 , antiproliferative activity of tested samples might be connected to active phytochemicals, purified from mentioned fractions reported in our previous study (19). Either luteolin, an abundant dietary component or chrysoeriol as well as their glycosides, are widely distributed in plant kingdom and possess a variety of pharmacological activities, including antiproliferative effects $(20,21)$. Thus, the antiproliferative activity of $40 \%$ SPE fraction might be discussed by the presence of 5-methoxyluteolin 7-O- $\beta$-D-glucopyranoside, Luteolin and chrysoeriol 7-O- $\beta$-D-glucopyranoside purified from $40 \%$ SPE fraction (19). Furthermore, the antiproliferative activity of $60 \%$ SPE fraction might be due to the presence of 5-methoxy Luteolin in this fraction, noted in our previous study (19). Moreover, 20\% SPE fraction demonstrated antiproliferative activity, which might be due to the presence of 4 , 6-di-methoxy acetophenone-2-O- $\beta$-D- glucopyranoside. The cytotoxicity of acetophenone derivatives have been found in some preceding researches (22, 23). However, further investigations are needed to separate and identify more potent phytochemicals, which play an important role in the antiproliferative activity of $40 \%$ and other active SPE fractions.

According to previous studies, different species of Artemisia genus not only demonstrated antiproliferative effects, but also antibacterial activities. MeOH extract of $A$. nilagirica was active against Escherichia coli, Bacillus subtilis, 
Table 2. The Antimicrobial Activity of the MeOH Extract and Fractions of A. spicigera as the Mean Inhibition Zone Diameter \pm SD (MIZD) and Minimum Inhibitory Concentration (MIC) of the Samples Against Different Strains $(\mathrm{n}=3)$

\begin{tabular}{|c|c|c|c|c|c|c|}
\hline \multirow[t]{2}{*}{ Samples } & \multicolumn{6}{|c|}{ MO } \\
\hline & & E. coli & P. aeruginosa & S. epidermidis & S. aureus & Candida albicans \\
\hline \multirow{2}{*}{ МеOH } & $\mathrm{MIZD} \pm \mathrm{SD}, \mathrm{mm}$ & - & - & $11 \pm 0.00$ & $11 \pm 1.40$ & - \\
\hline & MIC, mg/mL & - & - & 150 & 150 & - \\
\hline $10 \%$ & $\mathrm{MIZD} \pm \mathrm{SD}, \mathrm{mm}$ & - & - & - & - & - \\
\hline \multirow{2}{*}{$\mathbf{2 0} \%$} & $\mathrm{MIZD} \pm \mathrm{SD}, \mathrm{mm}$ & - & - & $75 \pm 7.00$ & $80 \pm 0.00$ & - \\
\hline & $\mathrm{MIC}, \mathrm{mg} / \mathrm{mL}$ & - & - & 35 & 35 & - \\
\hline \multirow{2}{*}{$40 \%$} & $\mathrm{MIZD} \pm \mathrm{SD}, \mathrm{mm}$ & - & - & - & - & - \\
\hline & MIC, mg/mL & - & - & - & - & - \\
\hline \multirow{2}{*}{$60 \%$} & $\mathrm{MIZD} \pm \mathrm{SD}, \mathrm{mm}$ & - & - & - & - & - \\
\hline & $\mathrm{MIC}, \mathrm{mg} / \mathrm{mL}$ & - & - & - & - & - \\
\hline \multirow{2}{*}{$\mathbf{8 0} \%$} & $\mathrm{MIZD} \pm \mathrm{SD}, \mathrm{mm}$ & - & - & - & - & - \\
\hline & $\mathrm{MIC}, \mathrm{mg} / \mathrm{mL}$ & - & - & - & - & - \\
\hline \multirow{2}{*}{$100 \%$} & $\mathrm{MIZD} \pm \mathrm{SD}, \mathrm{mm}$ & - & - & - & - & - \\
\hline & MIC, mg/mL & - & - & - & - & - \\
\hline
\end{tabular}

Abbreviations: MO, microorganisms; MeOH, methanolic extract; 10\%, SPE fraction 10\% MeOH-water; 20\%, SPE fraction 20\% MeOH-water; 40\%, SPE fraction 40\% MeOHwater; 60\%, SPE fraction 60\% MeOH-water; 80\%; SPE fraction 80\% MeOH-water; 100\%, SPE fraction 100\% MeOH.

Yersinia enterocolitica, Salmonella typhi, Enterobacter aerogenes, Proteus vulgaris, and Pseudomonas aeruginosa (24). Buffered methanol (80\% methanol and 20\% PBS) and acetone extracted substances from $A$. absinthium showed inhibitory activity against E. coli, S. infantis, S. aureus and L. monocytogenes (25). A. capillaris Thunb and A. caruifolia Buch were active against $B$. cereus and L. monocytogenes (26). Furthermore, A. annua and A. vulgaris L. var indica maxim possessed antimicrobial activity against streptococcus mutans (27). To the best of our knowledge, in reviewing the literature, there was no report about the antimicrobial activity of $A$. spicigera $\mathrm{MeOH}$ extract. The findings of this study revealed that MeOH extract and 20\% SPE fraction were active against $S$. epidermidis and $S$. aureus, which are both Gram-positive strains. The obtained results were consistant with the findings of previous studies and suggested that due to the several possible reasons mentioned in our previous study, the most susceptible strains were Grampositive microorganisms (28). The antibacterial effects of acetophenone derivatives have been previously shown against Staphylococcus aureus $(29,30)$. Therefore, the existence of 4, 6-di-methoxy acetophenone-2-O- $\beta$-D-glucopyranoside in $20 \%$ fraction and its antibacterial activity might be considered as a possible explanation for the inhibitory effect of the mentioned SPE fractions. Although flavonoids which have indicated antibacterial activities were purified from $40 \%$ and $60 \%$ SPE fractions (31-35), contrary to the expectations, these two fractions did not demonstrate any antibacterial activity against the tested strains. Further investigations are needed to separate and identify phytoconstituents, with the antibacterial activities in $40 \%$ and $60 \%$ SPE fractions.

Focusing on the biological activities of the herbs could lead to the discovery and development of new pharmaceuticals. Acetophenones derivatives may serve as a novel group of useful therapeutics against Gram- positive strains. In light of the present findings, $\mathrm{MeOH}$ extract of A. spicigera and its SPE fractions might be regarded as bioactive natural products and deserve to be further investigated for their potential therapeutic effects in both experimental models of tumor and infection. Future studies are encouraged to separate and identify the principal phytochemicals, with lower IC $_{50}$ values responsible for the observed biological activities of the tested $\mathrm{MeOH}$ extract and SPE fractions. Another possible area of future research would be to investigate the mechanisms underlying the cytotoxic and antibacterial effects of $\mathrm{MeOH}$ extract and fractions of $A$. spicigera as well as isolation and identification of principal phytoconstituents. 


\section{Acknowledgments}

We are grateful to Dr. Esnaashari for her valuable contributions to this study. This research was a part of a research project confirmed by drug applied research center, Tabriz University of Medical Sciences. Hereby, assistance and cooperation of the research deputy of Tabriz University of Medical Sciences and the participants are highly appreciated. Also, the authors declare that there is no conflict of interest.

\section{References}

1. Cowan MM. Plant products as antimicrobial agents. Clin Microbiol Rev. 1999;12(4):564-82. [PubMed: 10515903].

2. Mozaffarian V. Identification of medicinal and aromatic plants of Iran. Tehran: Farhang Mo'aser; 2013.

3. Mozaffarian V. A dictionary of Iranian plant names. Tehran: Farhang Mo'aser; 2007.

4. Ramezani M, Fazli-Bazzaz BS, Saghafi-Khadem F, Dabaghian A. Antimicrobial activity of four Artemisia species of Iran. Fitoterapia. 2004;75(2):201-3. doi: 10.1016/j.fitote.2003.11.006. [PubMed: 15030925].

5. Alanis AD, Calzada F, Cervantes JA, Torres J, Ceballos GM. Antibacterial properties of some plants used in Mexican traditional medicine for the treatment of gastrointestinal disorders. J Ethnopharmacol. 2005;100(1-2):153-7. doi: 10.1016/j.jep.2005.02.022. [PubMed: 16005589].

6. Abid Ali Khan MM, Jain DC, Bhakuni RS, Zaim M, Thakur RS. Occurrence of some antiviral sterols in Artemisia annua. Plant Sci. 1991;75(2):161-5. doi: 10.1016/0168-9452(91)90230-6.

7. Akrout A, Gonzalez LA, El Jani H, Madrid PC. Antioxidant and antitumor activities of Artemisia campestris and Thymelaea hirsuta from southern Tunisia. Food Chem Toxicol. 2011;49(2):342-7. doi: 10.1016/j.fct.2010.11.003. [PubMed: 21075159].

8. Juteau F, Masotti V, Bessiere JM, Dherbomez M, Viano J. Antibacterial and antioxidant activities of Artemisia annua essential oil. Fitoterapia. 2002;73(6):532-5. [PubMed: 12385883].

9. Choi E, Park H, Lee J, Kim G. Anticancer, antiobesity, and antiinflammatory activity of Artemisia species in vitro. J Tradit Chin Med. 2013;33(1):92-7. [PubMed: 23596819].

10. Khlifi D, Sghaier RM, Amouri S, Laouini D, Hamdi M, Bouajila J. Composition and anti-oxidant, anti-cancer and anti-inflammatory activities of Artemisia herba-alba, Ruta chalpensis L. and Peganum harmala L. Food Chem Toxicol. 2013;55:202-8. doi:10.1016/j.fct.2013.01.004. [PubMed: 23333573]

11. Heshmati Afshar F, Delazar A, Nazemiyeh H, Esnaashari S, Moghadam S. Comparison of the total phenol, flavonoid contents and antioxidant activity of methanolic extracts of Artemisia spicigera and A. splendens growing in Iran. Pharm Sci. 2012;18(3):165-70.

12. Heshmati Afshar F, Delazar A, Janneh O, Nazemiyeh H, Pasdaran A, Nahar L, et al. Evaluation of antimalarial, free-radical-scavenging and insecticidal activities of Artemisia scoparia and A. Spicigera, Asteraceae. Revista Brasileira de Farmacognosia. 2011;21(6):986-90.

13. Tofighi Z, Asgharian P, Goodarzi S, Hadjiakhoondi A, Ostad SN, Yassa N. Potent cytotoxic flavonoids from Iranian Securigera securidaca. Med Chem Res. 2014;23(4):1718-24.

14. Asgharian P, Heshmati Afshar F, Asnaashari S, Bamdad Moghaddam S, Ebrahimi A, Delazar A. Characterization of Terpenoids in the Essential Oil Extracted from the Aerial Parts of Scrophularia Subaphylla Growing in Iran. Adv Pharm Bull. 2015;5(4):557-61. doi: 10.15171/apb.2015.075. [PubMed: 26819929].
15. Balunas MJ, Kinghorn AD. Drug discovery from medicinal plants. Life Sci. 2005;78(5):431-41. doi: 10.1016/j.lfs.2005.09.012. [PubMed: 16198377].

16. Lam KS. New aspects of natural products in drug discovery. Trends Microbiol. 2007;15(6):279-89. doi:10.1016/j.tim.2007.04.001.[PubMed: 17433686].

17. Taghizadeh Rabe SZ, Mahmoudi M, Ahi A, Emami SA. Antiproliferative effects of extracts from Iranian Artemisia species on cancer cell lines. Pharm Biol. 2011;49(9):962-9. doi:10.3109/13880209.2011.559251. [PubMed: 21592012].

18. Gordanian B, Behbahani M, Carapetian J, Fazilati M. In vitro evaluation of cytotoxic activity of flower, leaf, stem and root extracts of five Artemisia species. Res Pharm Sci. 2014;9(2):91-6. [PubMed: 25657777].

19. Heshmati Afshar F, Delazar A, Nazemiyeh H, Khodaie L, Moghaddam S. Phenolic Derivatives of Artemisia Spicigera C. Koch Growing in Iran. Iran J Pharmaceutical Res. 2015;14(4):1241.

20. Yamabe N, Kang KS, Lee AY, Lee D, Choi JM, Lee S, et al. Identification of anti-cancer active components of Taraxacum coreanum on human gastric cancer AGS cells.J Korean Soc Appl Biol Chem. 2014;57(2):187-90.

21. Le Bail JC, Varnat F, Nicolas JC, Habrioux G. Estrogenic and antiproliferative activities on MCF-7 human breast cancer cells by flavonoids. Cancer Lett. 1998;130(1-2):209-16. [PubMed: 9751276].

22. Zhang N, Cai H, Cai B, Yang H, Li J, Yang G. Two new cytotoxic acetophenone derivatives from Euphorbia ebracteolata Hayata. Fitoterapia. 2010;81(5):385-8. doi:10.1016/j.fitote.2009.11.007. [PubMed: 19958822].

23. Yang $X$, Zhang YB, Wu ZN, Zhang XQ, Jiang JW, Li YL, et al. Six new prenylated acetophenone derivatives from the leaves of Acronychia oligophlebia. Fitoterapia. 2015;105:156-9. doi: 10.1016/j.fitote.2015.07.002. [PubMed: 26160157].

24. Ahameethunisa AR, Hopper W. Antibacterial activity of Artemisia nilagirica leaf extracts against clinical and phytopathogenic bacteria. BMC Complement Altern Med. 2010;10:6. doi: 10.1186/1472-6882-10-6. [PubMed: 20109237].

25. Alzoreky NS, Nakahara K. Antibacterial activity of extracts from some edible plants commonly consumed in Asia. Int J Food Microbiol. 2003;80(3):223-30. [PubMed: 12423924].

26. Shan B, Cai YZ, Brooks JD, Corke H. The in vitro antibacterial activity of dietary spice and medicinal herb extracts. Int J Food Microbiol. 2007;117(1):112-9. doi: 10.1016/j.ijfoodmicro.2007.03.003. [PubMed: 17449125].

27. Chen CP, Lin CC, Namba T. Screening of Taiwanese crude drugs for antibacterial activity against Streptococcus mutans. J Ethnopharmacol. 1989;27(3):285-95. [PubMed: 2615434].

28. Khodaie L, Delazar A, Lotfipour F, Nazemiyeh H. Antioxidant and Antimicrobial activity of Pedicularis sibthorpii Boiss. And Pedicularis wilhelmsiana Fisch ex. Adv Pharm Bull. 2012;2(1):89-92. doi: 10.5681/apb.2012.012. [PubMed: 24312775].

29. Sivakumar P, Sheshayan G, Doble M. Experimental and QSAR of Acetophenones as Antibacterial Agents. Chem Biol Drug Des. 2008;72(4):303-13.

30. Rajabi L, Courreges C, Montoya J, Aguilera RJ, Primm TP. Acetophenones with selective antimycobacterial activity. Lett Appl Microbiol. 2005;40(3):212-7. doi: 10.1111/j.1472-765X.2005.01657.x. [PubMed: 15715647].

31. Cushnie TP, Lamb AJ. Antimicrobial activity of flavonoids. Int J Antimicrob Agents. 2005;26(5):343-56. [PubMed: 16323269].

32. Albayrak S, Aksoy A, Sagdic O, Hamzaoglu E. Compositions, antioxidant and antimicrobial activities of Helichrysum (Asteraceae) species collected from Turkey. Food Chem. 2010;119(1):114-22.

33. Kuete V, Ngameni B, Simo CC, Tankeu RK, Ngadjui BT, Meyer JJ, et al. Antimicrobial activity of the crude extracts and compounds from Ficus chlamydocarpa and Ficus cordata (Moraceae). J Ethnopharmacol. 2008;120(1):17-24. doi: 10.1016/j.jep.2008.07.026. [PubMed: 18718518].

34. Mellou F, Lazari D, Skaltsa H, Tselepis AD, Kolisis FN, Stamatis H. Biocatalytic preparation of acylated derivatives of flavonoid glycosides enhances their antioxidant and antimicrobial activity. J Biotech- 
nol. 2005;116(3):295-304. doi: 10.1016/j.jbiotec.2004.12.002. [PubMed: 15707690].

35. Martins S, Amorim ELC, Sobrinho TP, Saraiva AM, Pisciottano MNC,
Aguilar CN, et al. Antibacterial activity of crude methanolic extract and fractions obtained from Larrea tridentata leaves. Indust Crops Prod. 2013;41:306-11. 